\title{
RESTUDO DE VARIABILIDADE DO DEPÓSITO DE MINÉRIO SULFETADO DO PROJETO AMBRÓSIA SUL DA VOTORANTIM METAIS - PARACATU/MG*
}

\section{Resumo}

Camilo José de Freitas Neto ${ }^{1}$ Eder Lúcio de Castro Martins ${ }^{2}$ Jorge Lucas Carvalho Bechir ${ }^{3}$

Marina de Menezes Lopes ${ }^{4}$ Lucas Monteiro Corrêa e Lopes ${ }^{4}$ Valério Metsavaht ${ }^{5}$

O objetivo deste trabalho foi estudar a variabilidade do depósito de zinco sulfetado do projeto Ambrósia Sul, da Votorantim Metais localizado em Paracatu - Minas Gerais, frente aos processos de beneficiamento e poder, assim, detalhar o comportamento geometalúrgico dos vários corpos de minério do depósito. Além do estudo da variabilidade dos corpos de minério, o trabalho também inclui testes em escala de bancada durante anos e semestres de operação: 2016, 2017/01, 2017/02, 2018/01, 2018/02, 2019. A metodologia do estudo é resumida nas fases de amostragem de testemunho de sondagem, composição das amostras representativas dos corpos de minério e anos e semestres de operação da mina, testes de moagem, peneiramento, flotação de bancada e caracterização mineralógica da alimentação e produtos dos testes. O teste de bancada desenvolvido neste trabalho, tem como objetivo principal verificar variações significativas entre os corpos mineralizados e/ou semestres de mina de operação, tornando possível identificar potenciais oportunidades de otimização do circuito de tratamento de minérios, maximizando o retorno financeiro de toda a jazida mineral.

Palavras-chave: Variabilidade; Geomertalugia; Zinco; Esfalerita.

\section{VARIABILITY STUDY OF THE SULPHIDE DEPOSIT OF THE AMBROSIA PROJECT}

\section{Abstract}

The objective of this work was to study the variability of the deposit of sulphide zinc Ambrosia South project, Votorantim Metais located in Paracatu - Minas Gerais, compared to beneficiation processes and can thus detail the geometallurgical behavior of the various bodies of ore deposit. In addition to the study of variability of ore bodies, the work also includes testing at bench scale for years and semesters of operation: $2016,2017 / 01,2017 / 02,2018 / 01,2018 / 02,2019$. The methodology of the study is summarized in the stages of drill core sampling, composition of representative samples of the ore bodies and years and semesters of mine operation, grinding tests, screening, bench flotation and mineralogical characterization of food and products testing. The bench test developed in this study has as main objective to verify significant differences between the mineralized bodies and / or semesters operating mine, making it possible to identify potential opportunities for optimization of mineral processing circuit, maximizing the financial return of the entire deposit mineral.

Keywords: Variability; Geometarllugy; Zinc; Esphalerite.

\footnotetext{
Geólogo, Geólogo Junior, Tecnologia Polimetálicos, Votorantim Metais, Vazante, Minas Gerais, Brasil. Eng. Metalurgista, Gerente de Tecnologia, Tecnologia Polimetálicos, Votorantim Metais, Vazante, MG, Brasil.

3 Eng. de Minas, Engenheiro Pleno, Tecnologia Polimetálicos, Votorantim Metais, Vazante, MG, Brasil.

4 Eng. de Minas, Engenheira Junior, Tecnologia Polimetálicos, Votorantim Metais, Vazante, MG, Brasil.

5 Eng. de Minas, Consultor de Engenharia, Tecnologia Polimetálicos, Votorantim Metais, Vazante, MG, Brasil.
} 


\section{INTRODUÇÃO}

O projeto da mina de Ambrósia Sul visa a lavra do depósito de minério sulfetado de Zinco (esfalerita, ZnS, como mineral minério) e Chumbo (galena, PbS, como mineral minério) para recuperação e produção de concentrados destes minerais. A jazida está localizada a nordeste da cidade de Paracatu (Minas Gerais).

O depósito é dividido em corpos de acordo com o posicionamento geográfico, sendo basicamente classificados como corpos W (oeste), C (central) e E (leste). A tabela 1 apresenta os nomes de todos os corpos da jazida de Ambrósia Sul que foram estudados neste trabalho.

Tabela 1 - Nome dos Corpos Ensaiados

\begin{tabular}{|c|}
\hline CORPO \\
\hline $\mathrm{W}$ \\
\hline $\mathrm{W}-2$ \\
\hline $\mathrm{W}-3$ \\
\hline $\mathrm{C}-1$ \\
\hline $\mathrm{C}-1 \mathrm{AUX}$ \\
\hline $\mathrm{C}-2$ \\
\hline $\mathrm{C}-2 \mathrm{AUX}$ \\
\hline $\mathrm{C}-3$ \\
\hline
\end{tabular}

\begin{tabular}{|c|}
\hline CORPO \\
\hline C-3 AUX \\
\hline C-4 \\
\hline CE-1 \\
\hline CE-2 \\
\hline$E$ \\
\hline E-2 \\
\hline E-3 \\
\hline E-4 \\
\hline
\end{tabular}

O objetivo deste trabalho foi de estudar a variabilidade do depósito de sulfetos de Ambrósia frente aos processos de beneficiamento, podendo assim determinar as performances geometalúrgicas dos diversos corpos da mina. Além do estudo de variabilidade dos corpos mineralizados, o trabalha também abrange testes em escala de bancada para os seguintes anos e semestres de operação: 2016, 2017/01, 2017/02, 2018/01, 2018/02, 2019. Fernandes [1] citou a importância do estudo de variabilidade para compreender e operacionalizar as reservas minerais em curto, médio e longo prazo.

Malgahn [2] apresentou que diversos aspectos interferem na eficiência do processo de concentração, além do teor de alimentação, o tamanho do grão, grau de oxidação e composição mineralógica são variáveis que devem ser estudadas nas diversas regiões de um depósito mineral. Os estudos de variabilidade desenvolvidos em escala laboratorial permitem aperfeiçoar o conhecimento do comportamento do minério estudado no processo de beneficiamento, dessa forma inúmeras oportunidades de otimização são identificadas. Bianchi [3] ressaltou que a recuperação de metal nas plantas de beneficiamento são afetadas pela alta variabilidade de teores e, que, a recuperação pode ser maximizada quando as principais variáveis do minério que impactam em sua beneficiamento são mantidos em intervalos estreitos de variação.

\section{MATERIAIS E MÉTODOS}

A metodologia do estudo se resume nas fases de amostragem dos testemunhos de sondagem, composição das amostras referentes aos corpos mineralizados e aos anos e semestres de operação da mina, realização dos testes de moagem, granuloquímica, flotação em bancada e caracterização mineralógica da alimentação e produtos dos testes. 
O plano de amostragem para a realização dos testes foi realizado de acordo com o banco de dados de pesquisa mineral, da equipe de geologia do projeto Ambrósia, considerando todos os corpos mineralizados e os anos e semestres de operação. A figura 1 e 2 apresentada a distribuição espacial das Wireframes dos corpos mineralizados ensaiados e os anos e semestres de operação, respectivamente. As amostras selecionadas de testemunhos de sondagem são rejeitos grosseiros com granulometria menor que $2 \mathrm{~mm}$.

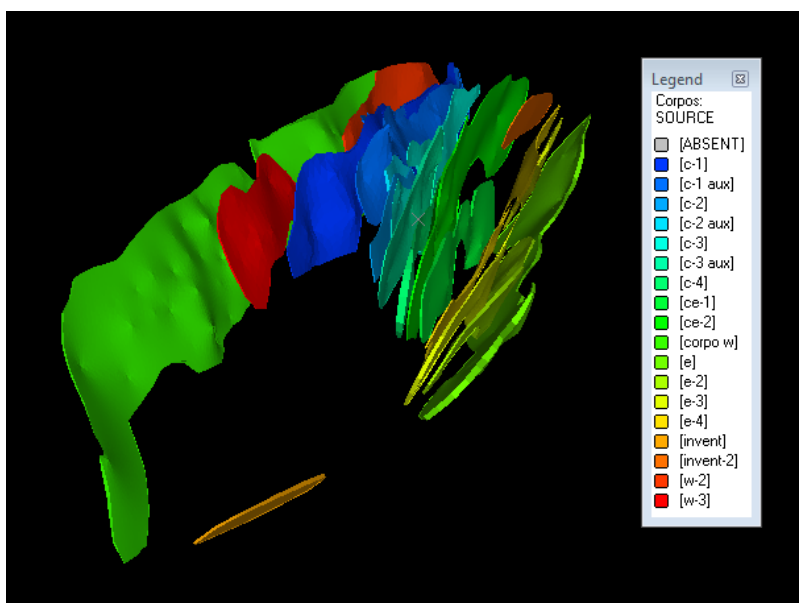

Figura 1 - Wireframes dos Corpos Mineralizados

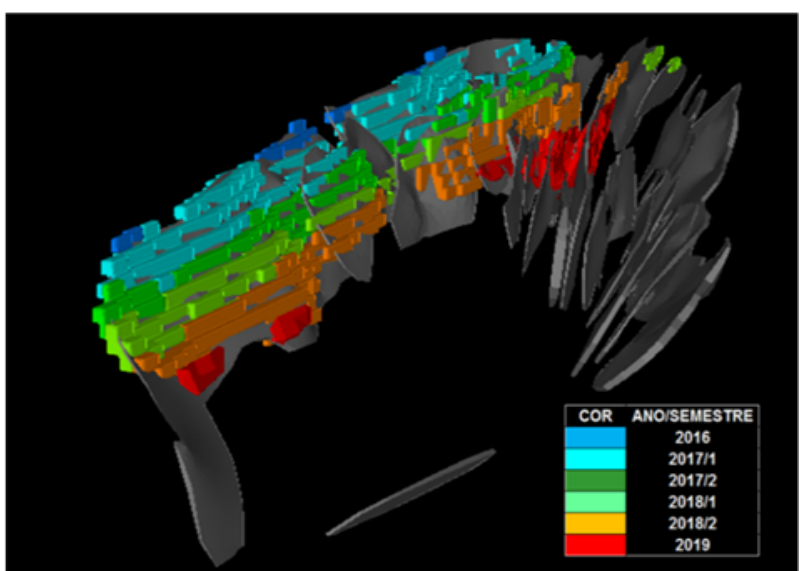

Figura 2 - Wireframes dos Anos e Semestres de Operação

As amostras compostas seguiram a premissa de se encontrar o teor de zinco de acordo com o teor de sequenciamento do sólido com um erro relativo máximo de $10 \%$. A tabela 1 apresenta os teores encontrados nas composições dos corpos mineralizados e dos anos e semestres de operação, tais valores foram compostos de acordo com o teor de sequenciamento dos sólidos. 
Tabela 2 - Teores das Amostras Compostas

TEORES

\begin{tabular}{|c|c|c|}
\hline AMOSTRA & $\mathrm{Zn}(\%)$ & $\mathrm{Pb}(\%)$ \\
\hline C1 & 5,67 & 0,44 \\
\hline C1 AUX & 4,96 & 0,15 \\
\hline $\mathrm{C} 2$ & 2,68 & 0,04 \\
\hline C2 AUX & 2,46 & 0,05 \\
\hline C3 & 4,25 & 0,06 \\
\hline C3 AUX & 4,36 & 0,11 \\
\hline C4 & 3,60 & 0,09 \\
\hline CE1 & 2,46 & 0,03 \\
\hline CE2 & 3,76 & 0,05 \\
\hline$E$ & 4,33 & 0,12 \\
\hline E2 & 3,76 & 0,05 \\
\hline E3 & 2,52 & 0,04 \\
\hline E4 & 2,72 & 0,05 \\
\hline W & 7,80 & 0,42 \\
\hline W2 & 5,05 & 0,10 \\
\hline W3 & 4,84 & 0,23 \\
\hline
\end{tabular}

TEORES

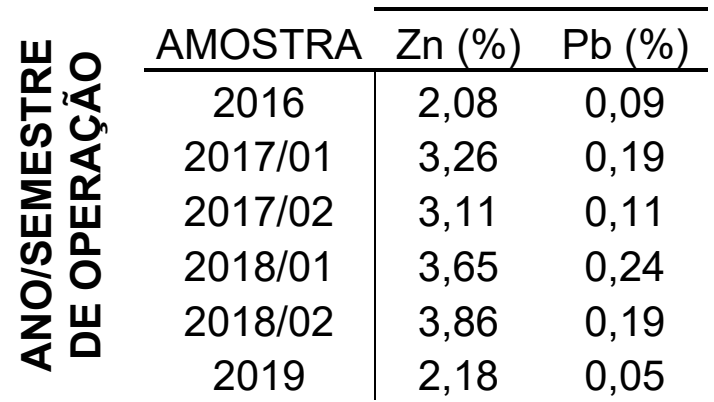

A primeira etapa de testes depois da composição das amostras é a moagem, a fim de reduzir a granulometria do material para os testes de flotação. Para o moinho de bancada utilizado neste trabalho as amostras compostas foram todas reduzidas a $100 \%$ passante em $1,18 \mathrm{~mm}$ em alíquotas de $1,3 \mathrm{~kg}$. A especificação granulométrica adotada nos testes foi definida de acordo com ensaios de liberação e o valor foi de $65 \%$ menor que $325 \#(0,044 \mathrm{~mm})$ para o produto da moagem. Após os testes de moagem o produto segue para os testes de granuloquímica.

O principal objetivo dos estudos de granuloquímica é identificar a distribuição dos elementos úteis em diversas granulometrias, podendo assim determinar a liberação ideal dos minerais de interesse. Tais informações, aliadas aos estudos de caracterização mineralógica, são fundamentais para o processo de concentração por flotação. O procedimento para o teste de granuloquímica é a coleta de uma alíquota do produto da moagem de bancada e o peneiramento a úmido nas malhas: 65,100 , $200,250,325,400$ e <400\#. A massa de cada peneira é então seca em estufa, pesada e enviada a análise química.

A flotação da galena e esfalerita se dá de maneira sequencial, sendo o rejeito da etapa scavenger da galena a alimentação da flotação da esfalerita, como pode ser visto na figura 4 que exemplifica o fluxograma utilizado nos testes.

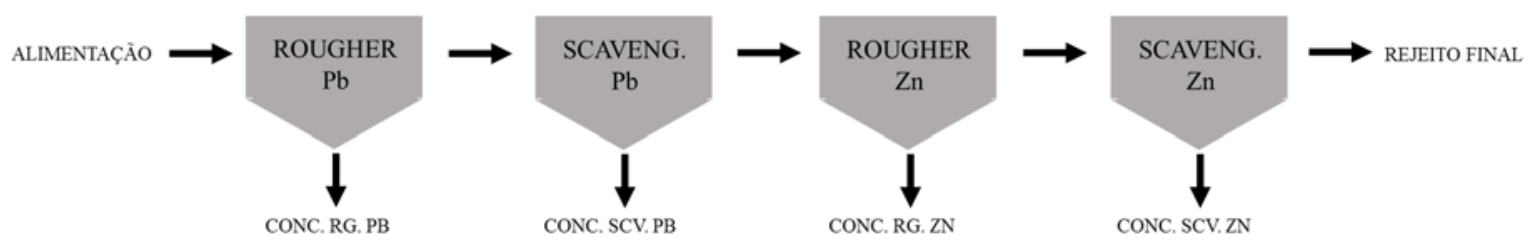

Figura 4 - Fluxograma dos Testes em Flotação de Bancada. 
Os reagentes utilizados nos testes de flotação são descritos na tabela 4. Já as variáveis mantidas constantes durante os testes de flotação da galena e esfalerita são apresentadas nas tabelas 5 e 6 , respectivamente.

Tabela 3 - Reagentes Utilizados nos Testes de Flotação REAGENTE

FUNÇÃO

\begin{tabular}{r|l} 
CAL: & MODULADOR DE pH \\
MIBCOL: & ESPUMANTE \\
ISOPROPIL XANTATO DE SÓDIO: & COLETOR DA GALENA \\
AMIL XANTATO DE POTÁSSIO: & COLETOR DA ESFALERITA \\
SULFATO DE COBRE: & ATIVADOR DA ESFALERITA
\end{tabular}

Tabela 4 - Padrão do Teste de Flotação da Galena

ETAPA VARIÁVEL

\begin{tabular}{c|l}
\hline MOAGEM & DOSAGEM DO COLETOR: $35 \mathrm{~g} / \mathrm{t}$ \\
\hline & DOSAGEM DO MODULADOR DE pH ATÉ 9,5 \\
& DOSAGEM DE ESPUMANTE: $20 \mathrm{~g} / \mathrm{t}$ \\
ROUGHER & TEMPO DE CONDICIONAMENTO DO ESPUMANTE: 2 minutos \\
& VAZÃO DE AR: 10 LPM \\
& ROTAÇÃO DA CÉLULA: $1700 \mathrm{rpm}$ \\
& TEMPO DE FLOTAÇÃO: 5 minutos \\
\hline SCAVENGER & DOSAGEM DO COLETOR E ESPUMANTE: $15 \mathrm{~g} / \mathrm{t}$ e $10 \mathrm{~g} / \mathrm{t}$ \\
DO Pb & TEMUTO DE CONDICIONAMENTO DO COLETOR E ESPUMANTE: 5 \\
& ROTAÇÃO DA CÉLULA: 1700 rpm \\
& TEMPO DE FLOTAÇÃO: 5 minutos
\end{tabular}

Tabela 5 - Padrão do Teste de Flotação da Esfalerita

ETAPA

\begin{tabular}{|c|c|}
\hline \multirow{3}{*}{$\begin{array}{c}\text { ROUGHER } \\
\text { DO Zn }\end{array}$} & DOSAGEM DO MODULADOR DE pH ATÉ 9,5 \\
\hline & $\begin{array}{l}\text { DOSAGEM DO ATIVADOR, COLETOR E ESPUMANTE: } 150 \mathrm{~g} / \mathrm{t} \text {, } \\
50 \mathrm{~g} / \mathrm{t} \text { e } 18 \mathrm{~g} / \mathrm{t} \\
\text { TEMPO DE CONDICIONAMENTO DO ATIVADOR, COLETOR E } \\
\text { ESPUMANTE: } 8 \text { minutos } \\
\text { VAZÃO DE AR: } 10 \text { LPM } \\
\text { ROTAÇÃO DA CÉLULA: } 1700 \mathrm{rpm}\end{array}$ \\
\hline & TEMPO DE FLOTAÇÃO: 5 minutos \\
\hline \multirow{3}{*}{$\begin{array}{c}\text { SCAVENGER } \\
\text { DO Zn }\end{array}$} & DOSAGEM DE COLETOR E ESPUMANTE: $50 \mathrm{~g} / \mathrm{t}$ e $12 \mathrm{~g} / \mathrm{t}$ \\
\hline & $\begin{array}{l}\text { TEMPO DE CONDICIONAMENTO DO COLETOR E } \\
\text { ESPUMANTE: } 3 \text { minutos } \\
\text { VAZÃO DE AR: } 10 \text { LPM } \\
\text { ROTAÇÃO DA CÉLULA: } 1700 \text { rpm }\end{array}$ \\
\hline & TEMPO DE FLOTAÇÃO: 5 minutos \\
\hline
\end{tabular}




\section{RESULTADOS E DISCUSSÃO}

\subsection{MOAGEM E GRANULOQUÍMICA}

O gráfico 1 apresenta a variação da distribuição, porcentagem de metal contido, dos elementos $\mathrm{Zn}$ e $\mathrm{Pb}$, respectivamente, por faixas granulométricas de todos os testes realizados neste trabalho para o projeto Ambrósia Sul. É possível concluir que tanto o zinco quanto o chumbo estão preferencialmente nas frações ultrafinas, menores que $400 \#(0,044 \mathrm{~mm})$. É importante alertar que tais resultados não permitem afirmar como os elementos de interesse ocorrem, associados ou liberados, estas informações são confirmadas através de estudos de caracterização tecnológica de minérios contidas, também, neste estudo. Outro ponto a observar é a pouca ocorrência dos metais nas frações mais grosseiras de $65(0,21 \mathrm{~mm})$ e $100 \#(0,15 \mathrm{~mm})$, indicando a possibilidade de descarte deste material sem que ele passe necessariamente pela etapa de concentração.

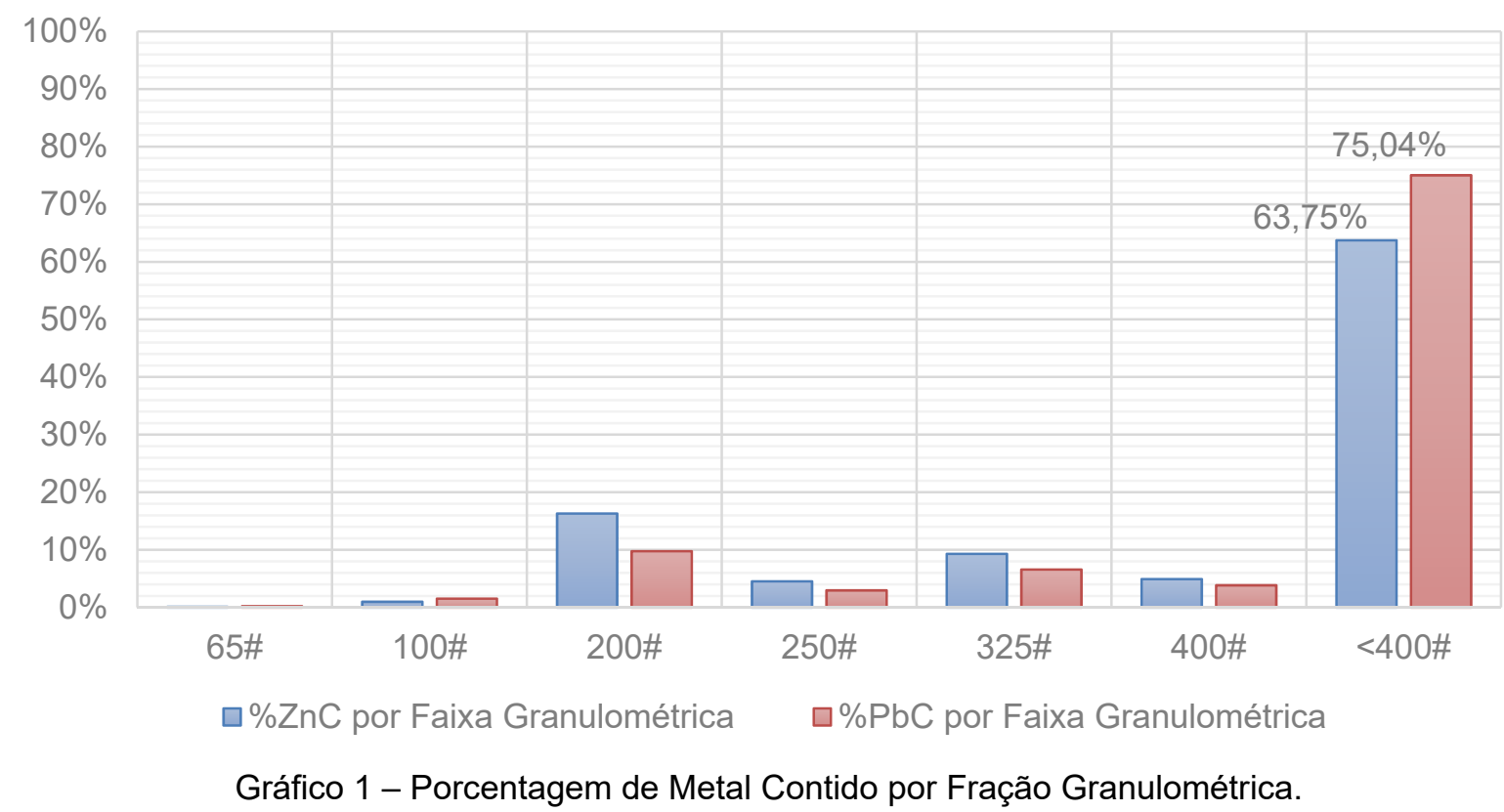

\subsection{FLOTAÇÃO}

Os gráficos 2 e 3 apresenta todos os valores de recuperação metalúrgica, mássica e teores de concentrados rougher de chumbo e zinco, respectivamente, obtidos nos testes de flotação dos corpos mineralizados.

Para a flotação da galena notou-se uma grande variação nas recuperações metalúrgicas e pouco arraste de massa, o que pode ser explicado pelos baixos teores de chumbo na alimentação. As maiores recuperações atingidas nos testes $\mathrm{C} 1, \mathrm{~W}$ e W3 foram com os maiores teores de chumbo na alimentação: $0.44,0.42$ e $0.23 \%$, respectivamente. Os teores de concentrado rougher atingidos nos testes indicam a necessidade de etapas de limpeza para obter concentrados com teores mais elevados.

Para a flotação da esfalerita a recuperação do zinco registrou $75 \%$ dos valores entre 86.24 a $94.33 \%$. As menores recuperações atingidas foram nos testes W e W2, 65.51 e $78.54 \%$, respectivamente. $\mathrm{O}$ corpo $\mathrm{W}$ foi o teste com o maior teor de alimentação 
de zinco, 7,63\% e corresponde ao corpo mineralizado de maior massa na jazida de Ambrósia. A baixa recuperação deste teste pode ser explicada pela baixa dosagem de reagentes ante o alto teor de zinco na entrada, uma vez que o ativador e o coletor da esfalerita podem ter sido consumidos antes mesmo que todas as partículas minerais estivessem ativadas e coletadas, indo assim para o rejeito. Os resultados de caracterização mineralógica auxiliam no entendimento da má performance do teste. De maneira geral a produção de concentrado rougher foi satisfatória em termos de teores de zinco, mostrando pouca dificuldade em enriquecimento, sendo possível afirmar que com etapas de limpeza não haverá dificuldades em atingir os teores praticados comercialmente.

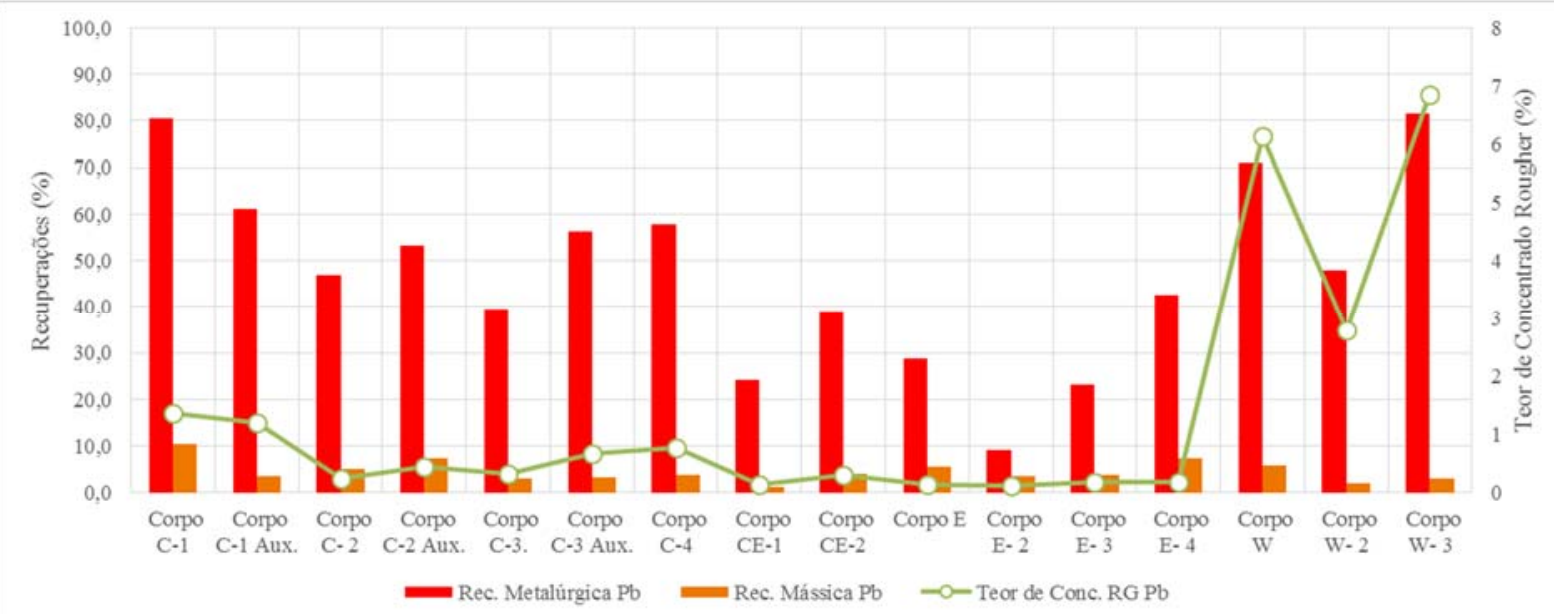

Gráfico 2 - Recuperações Metalúrgicas, Mássicas e Teores de Conc. Rougher de Chumbo

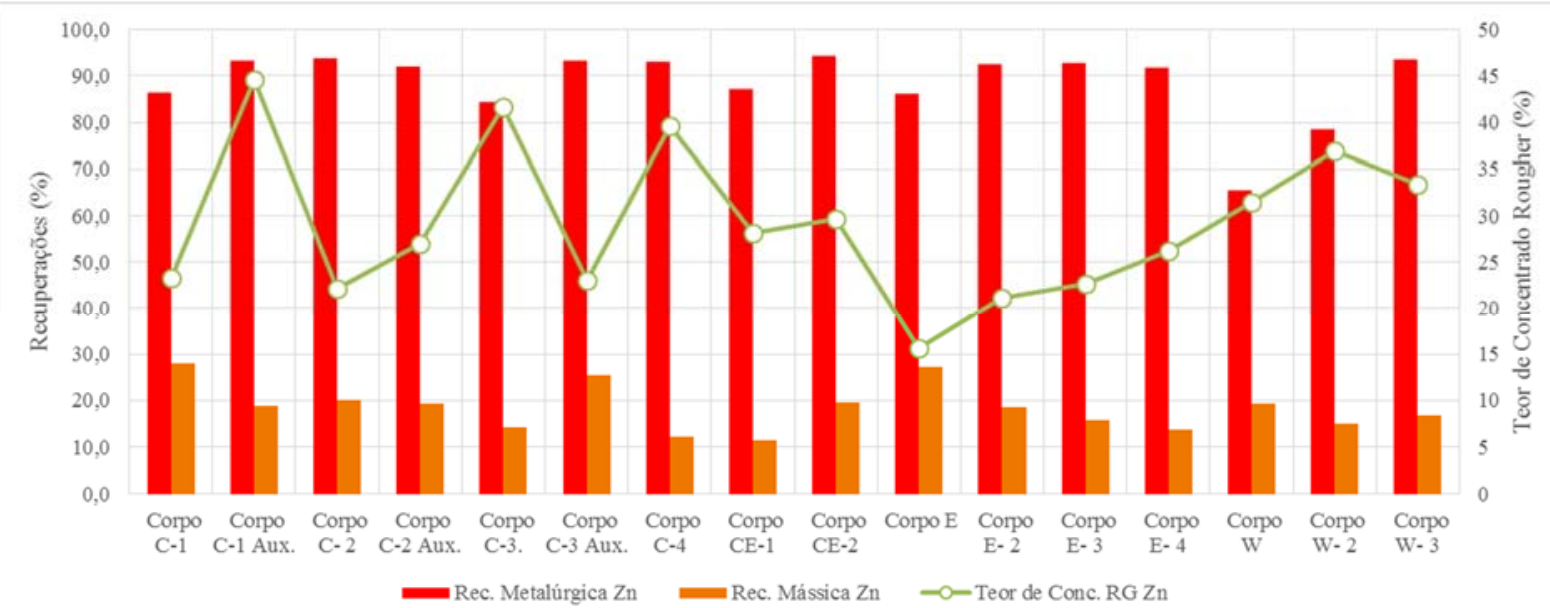

Gráfico 3 - Recuperações Metalúrgicas, Mássicas e Teores de Conc. Rougher de Zinco

O gráfico 4 e 5 apresenta todos os valores de recuperação metalúrgica, mássica e teores de concentrados rougher de chumbo e zinco, respectivamente, obtidos nos testes de flotação dos anos/semestres de operação.

Para a flotação da galena notou-se que a recuperação metalúrgica dos testes 2016 ficou bem abaixo dos resultados obtidos nos outros testes. É pertinente dizer que a amostra do teste 2016 foi composta por apenas furos de diluição, ou seja, furos que não interceptam os corpos mineralizados, enquanto as amostras restantes foram compostas tanto por furos de diluição quanto furos que interceptam os corpos mineralizados da jazida de Ambrósia Sul. As maiores recuperações metalúrgicas obtidas foram nos testes 2017/01, 2018/01 e 2018/02, justamente com os maiores 
teores de chumbo na alimentação: $0.13,0.20$ e $0.17 \%$. Os resultados de teores de concentrados rougher alcançados indicam a necessidade de etapas de limpeza e recirculação de massa rica para que se atinja patamares de $55 \%$ de $\mathrm{Pb}$ no concentrado final, o que implicaria em redução de recuperação de massa no concentrado e consequente redução da recuperação metalúrgica para este metal.

Para a flotação da esfalerita percebeu-se pouca variabilidade nos resultados obtidos. A participação de furos de diluição nas composições das amostras também impactou na flotação do zinco, gerando recuperações menores que as atingidas nos testes com os corpos mineralizados. A fim de maximizar a recuperação nas etapas rougher e scavenger pode-se trabalhar com um maior arraste de massa e uma queda aceitável no concentrado rougher, uma vez que é necessária etapa de limpeza para produção de concentrado com teores de $37.5 \%$ de zinco. O teste 2019 representa este cenário, onde houve um maior arraste de massa e a maior recuperação metalúrgica obtida nesta batelada de testes.

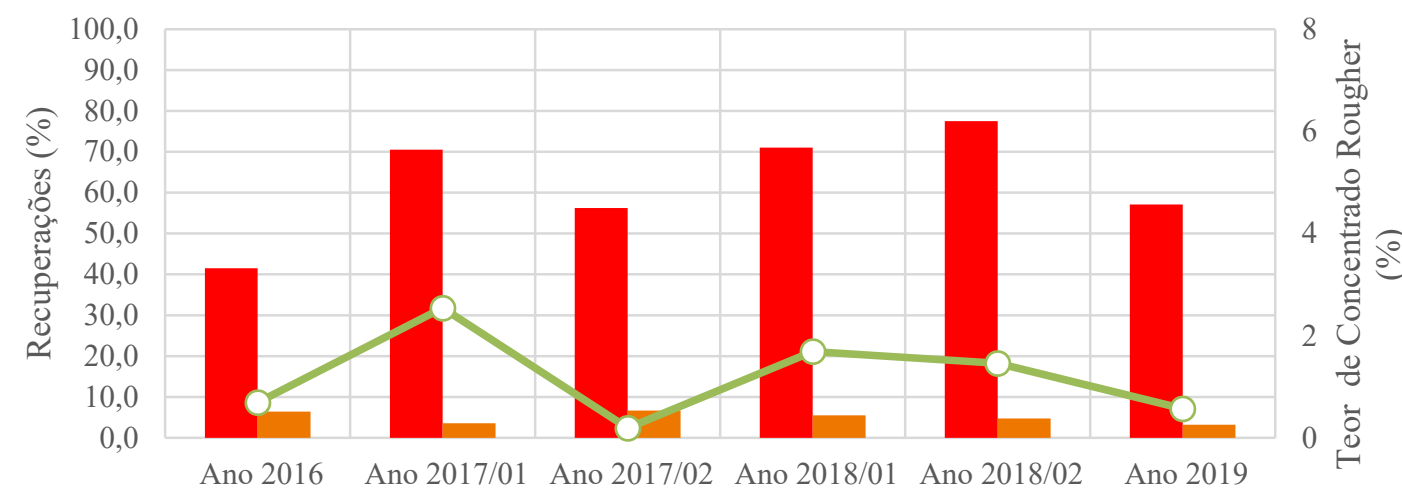

Rec. Metalúrgica $\mathrm{Pb} \quad$ Rec. Mássica $\mathrm{Pb} \quad \mathrm{O}=$ Teor de Conc. RG Pb

Gráfico 4 - Recuperações Metalúrgicas, Mássicas e Teores de Conc. Rougher de Chumbo

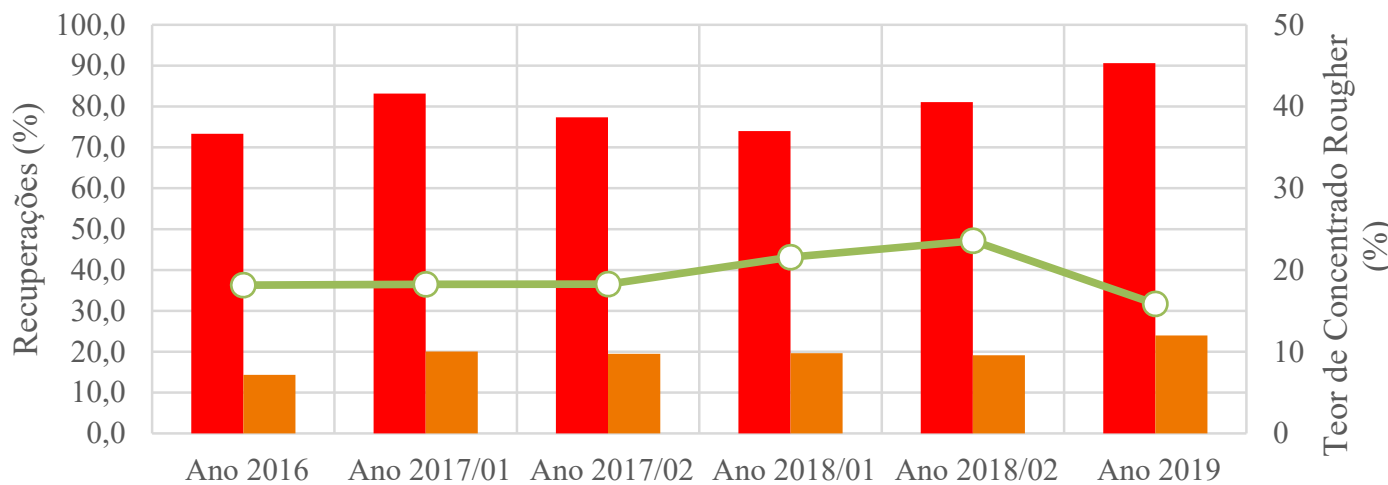

Rec. Metalúrgica Zn $\quad$ Rec. Mássica Zn $\quad$ - $\quad$ Teor de Conc. RG Zn

Gráfico 5 - Recuperações Metalúrgicas, Mássicas e Teores de Conc. Rougher de Zinco

\section{CONCLUSÃO}

Através dos testes de granuloquímica foi possível identificar que os elementos de interesse, chumbo e zinco, se encontram nas frações mais finas, menores que $0.038 \mathrm{~mm}$. Além disso, foi possível verificar que nas frações mais grosseiras $(0.21 \mathrm{~mm})$ as ocorrências de chumbo e zinco são raras. 
A flotação de chumbo nos testes dos corpos mineralizados apresentou uma variação considerável de recuperação metalúrgica. De modo geral o conjunto de mineralizações dos corpos $\mathrm{C} \mathrm{e} \mathrm{W}$ apresentaram as recuperações mais elevadas. Nota-se, também, que os maiores teores de concentrado rougher foram atingidos nas mineralizações do corpo W. Destaca-se o fato de que os corpos C1, W e W3 foram os testes com as maiores recuperações de chumbo, tendo estas amostras os maiores teores de $\mathrm{Pb}$ na alimentação do teste. Já para a flotação de zinco nos testes com a amostras das mineralizações não foi observada uma variação significativa da recuperação metalúrgica. Para a variável teor de concentrado foi constatado uma grande variação além de ter atingido níveis de teores altos para uma etapa rougher de flotação, essencialmente recuperadora.

As amostras compostas dos anos e semestres de operação do depósito de Ambrósia submetidas aos testes de flotação de chumbo também mostraram uma variação para a recuperação metalúrgica da galena. O ano de 2016 alcançou o menor valor observado durante esta batelada de testes. Outro fato que foi observado nos testes com as amostras referentes aos períodos de operação da mina de Ambrósia foi que os testes com os maiores teores de alimentação $(2017 / 1,2018 / 1$ e 2018/2) de chumbo atingiram as melhores recuperações metalúrgicas, o que foi identificado nos testes com as mineralizações, evidenciando assim correlação entre estas variáveis. A pequena variação da recuperação metalúrgica na flotação do zinco das amostras dos corpos mineralizados também foi observada na segunda batelada de testes, embora que os valores atingidos nesta segunda etapa foram menores, fato atribuído a participação de furos de diluição. Houve também um enriquecimento considerável para a etapa rougher de flotação.

\section{REFERÊNCIAS}

1 Fernandes, E.Z. Aplicação da Caracterização Tipológica ao Planejamento de Lavra de Minério de Ferro; Dissertação de Mestrado; Universidade Federal de Minas Gerais; 2003.

2 Malgahan, S.G. Treatment Methods for Difficult-to-Float Copper Porphyry Ores; Mining Engineering; Sept. 1986.

3 Bianchi et all. Estudo de Variabilidade de ROM (Run of Mine) Usando Ferramentas de Simulação e Otimização. 